\title{
Comparing Values of Protein and Fat by Composition-based Method and Conventional Method
}

\section{Tatsuya Koyama*}

Aomori University of Health and Welfare, Japan

*Corresponding Author: Tatsuya Koyama, Aomori University of Health and Welfare, Japan.
Received: April 05, 2021

Published: May 11, 2021

(C) All rights are reserved by Tatsuya Koyama.

\section{Abstract}

AThe revised version of the Standard Tables of Food Composition in Japan (STFCJ 2020) was published in 2020. The aim of the present paper is to discuss issues concerning calculation of protein and fat using food components listed in STFCJ 2020. In SFTCJ 2020, in addition to conventional values of protein content calculated as reference nitrogen multiplied by protein conversion factor $<\mathrm{XN}>$ (PROTRN) and gravimetrically determined fat (FAT), values of protein were expressed as the sum of amino acid residues $<$ PROTCAA $>$ and values of lipids as triacylglycerol equivalents of fatty acids $<$ FATNLEA $>$. Protein and fat contents were significantly decreased when the preferred analytical methods of the United Nations Food and Agriculture Organization (PROTRN and FATNLEA) were applied instead of the conventional values. Therefore, it is important to compare calculated protein and fat using PROCTAA and FATLEA to calculations from previous studies of protein and fat.

Keywords: Protein; Fat; Sum of Amino Acid Residues; Triacylglycerol Equivalents of Fatty Acids; Food Composition Table

\section{Abbreviations}

CI: Confidence Interval; EP: Edible Portion; FAO: The United Nations Food and Agriculture Organization; FAT: Gravimetrically Determined Fat; FATNLEA: Lipids as Triacylglycerol Equivalents of Fatty Acids; INFOODS: The International Network of Food Data Systems; NT: Total Nitrogen; PROTRN: Protein Content Calculated by Reference Nitrogen Multiplied by Protein Conversion Factor; PROTRN: Protein Content Calculated by Sum of Amino Acid Residues; SD: Standard Deviation; STFCJ: Standard Tables of Food Composition in Japan; XN: Protein Conversion Factor

\section{Introduction}

Food composition tables are an important source of information for health studies. These tables are generally constructed on a country-by-country basis, describing nutritional information relevant to the primary foods in each country. Such information can be used in local and global nutritional epidemiology research to enrich the lives of people both in the country in question and around the world.
A global food composition database was constructed by the United Nations Food and Agriculture Organization (FAO) based on food composition tables from every country in the world. To improve this database, the FAO has organized the International Network of Food Data Systems (INFOODS) [1].

The revised version of the Standard Tables of Food Composition in Japan (STFCJ) was published in 2020 [2]. STFCJ lists two food components as proteins: protein calculated using amino acid components $<$ PROTCAA $>$ and protein content calculated as reference nitrogen multiplied by a nitrogen to protein conversion factor $<$ PROTRN $>$. STFCJ also lists two food components as fat: fatty acid components $<$ FATNLEA $>$ and gravimetrically determined fat $<$ FAT > . In STFCJ 2020, the calculation of energy values was changed, and they were calculated using a method proposed by FAO which uses amino acid components, fatty acid components, and carbohydrate components. The FAO recommends that proteins in foods should be measured as the sum of individual amino acid residues plus free amino acids, and that fats should be analyzed as fatty 
acids and expressed as triacylglycerol equivalents, namely, protein calculated as the sum of the amino acid residues $<$ PROTCAA $>$ and fat expressed as the triacylglycerol equivalent of fatty acids $<$ FATNLEA>.

\section{Aim of the Study}

The aim of the present paper is to discuss issues concerning how to calculate protein and fat using food components listed in STFCJ 2020. Note: Throughout this paper INFOODS' tag names, $<$ TAGNAME>, are used as the component identified and abbreviations for the components.

\section{Materials and Methods}

Amino acid composition was determined using the methods described in the STFCJ [2]. STFCJ 2020 lists 1,939 foods with PROTCAA in its main tables. Protein content was calculated as reference nitrogen multiplied by a nitrogen to protein conversion factor $<\mathrm{XN}>$ (PROTRN) (Note: reference nitrogen is an approximation for proteinous nitrogen and is calculated as nitrogen in nitrate, caffeine, and theobromine subtracted from total nitrogen $<$ NT $>$. Accordingly, when a food does not contain nitrate, caffeine, or its reference nitrogen content is considered equal to NT, its PROTRN content equals protein $<$ PROT $>$ calculated as NT multiplied by XN). Percent energy from PROTCAA or PROTRN of a food (\%E) was calculated as PROCTAA or PROTRN (g/100 g EP), multiplied by the energy conversion factor of protein ( $4 \mathrm{kcal} / \mathrm{g}$ ), divided by energy (kcal/100 g EP).

The 1,927 foods with FATNLEA are listed in the main tables of the STFCJ [2]. Total fat $<$ FAT $>$ content was determined by the methods described in the STFCJ.

The following formula was used to convert all individual fatty acid contents to FATNLEA:

FATNLEA $(\mathrm{g})=\Sigma[$ fatty acid $(\mathrm{g}) \times(\mathrm{MW}+12.68) / \mathrm{MW}]$

Where MW is the molecular weight of the fatty acid, and 12.68 is the additional formula weight per fatty acid when converting a fatty acid to its triacylglycerol equivalent. This value is calculated as the molecular weight of glycerol (92.09) divided by three because glycerol binds to three fatty acids in triacylglycerol, and then the molecular weight of water (18.02), which is lost by ester bond formation, is subtracted. The percent energy from FATNLEA or FAT of a food (\%E) was calculated as FATNLEA or FAT (g/100 g EP) multiplied by the energy conversion factor of fat $(9 \mathrm{kcal} / \mathrm{g})$ divided by energy (kcal/100 g EP).

\section{Results and Discussion}

The correlation between PROTCAA and PROTRN values per 100 $\mathrm{g}$ of edible portion (EP) was significant $(r=0.990, \mathrm{p}<0.001)$, but there was an apparent difference between the lines of equality. The content of PROTCAA was significantly lower than that of PROTRN (Figure 1a): the mean difference was $1.7 \mathrm{~g} / 100 \mathrm{~g}$ EP and the standard deviation of the difference (SD) was 2.1; the $95 \%$ confidence interval (CI) was 1.6 to 1.8 ( $p<0.001)$ ( $n=1,939)$. A considerable difference between PROTRN and PROTCAA was found in fish and shellfish because of the portable presence of amines, which are measured as PROTRN in the STFCJ 2020. The correlation between percent energy from PROTCAA and percent energy from PROTRN was significant $(r=0.985, p<0.001)$, but there was an apparent difference between the lines of equality. The percent energy from PROTCAA was significantly lower than the percent energy from PROTRN (Figure 1b): mean d was 5.6\%E and SD was 6.4; and 95\% CI was 5.4 to $6.0(\mathrm{p}<0.001)(\mathrm{n}=1,939)$. A considerable difference between PROTRN and PROTCAA was found in fish and shellfish because of the portable presence of amines, which are measured as PROTRN in the STFCJ 2020.

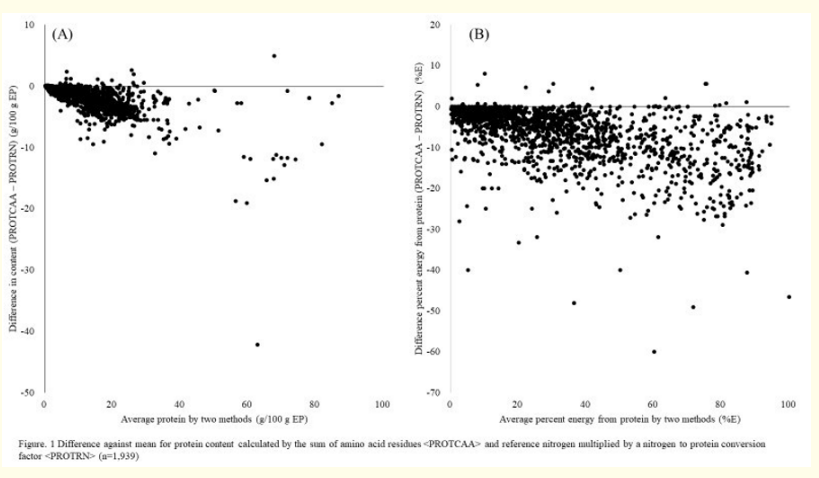

Figure 1: Difference against mean for protein content calculated by the sum of amino acid residues $<$ PROTCAA $>$ and reference nitrogen multiplied by a nitrogen to protein conversion factor $<$ PROTRN $>(\mathrm{n}=1.939)$.

There was a significant correlation between FATNLEA and FAT ( $r=0.998, p<0.001)$; FATNLEA was, however, significantly lower than FAT (Figure 2a): d was $0.9 \mathrm{~g} / 100 \mathrm{~g}$ EP and SD was 1.4; $95 \% \mathrm{CI}$ was 0.8 to $1.0(\mathrm{p}<0.001)(\mathrm{n}=1,927)$. This is reasonable because the gravimetrically determined fat also contains non-fat components. There was a significant correlation between percent energy from FATNLEA and percent energy from FAT $(r=0.991, p<$ 0.001). Percent energy from FATNLEA was, however, significantly 
lower than the percent energy from FAT (Figure $2 \mathrm{~b}$ ): mean difference was $4.0 \% \mathrm{E}$ and SD was $4.2 ; 95 \%$ CI was 3.8 to 4.2 ( $\mathrm{p}<0.001)$ $(\mathrm{n}=1,927)$.

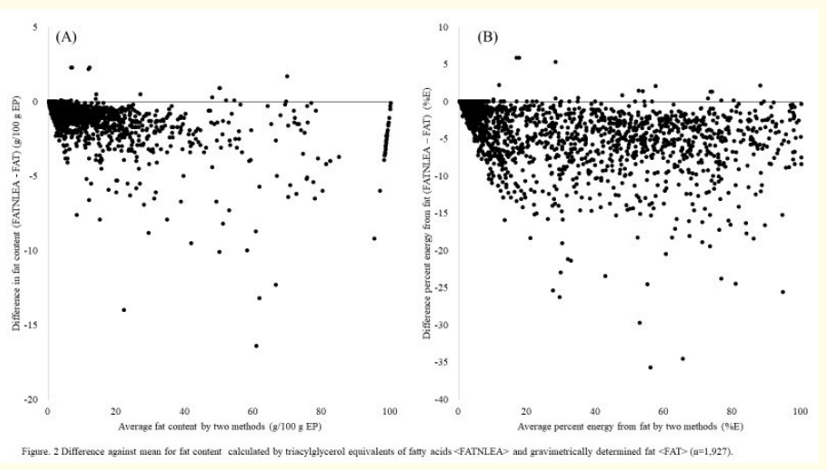

Figure 2: Difference against mean for fat content calculated by triacylglycerol equivalent of fatty acids $<$ FATNLEA $>$ and gravimetrically determined fat $<$ FAT $>(n=1.927)$.

In the Dietary Reference Intakes for Japanese 2020, reference values of protein are set as estimated average requirement (EAR), recommended dietary allowance (RDA), and the tentative dietary goal for preventing life-style related disease (DG). Reference values of total fat are set as DG [3]. EAR and RDA of protein are represented in grams per day and are determined by studies of nitrogen balance. In nitrogen balance tests, protein values are literally estimated from nitrogen [4]. Accordingly, it may be more appropriate to calculate protein intake in PROTRN when comparing protein intake to EAR and RDA.

The energy values per $100 \mathrm{~g}$ EP were calculated for listed foods in STFCJ 2020 by a method proposed by the FAO (i.e., PROTCAA, FATNLEA, and CHOAVLM [available carbohydrate]). Therefore, the percent energy from protein and fat may have to be calculated using PROCTAA and FATLEA, respectively, because the sum of percent energy from protein, fat, and carbohydrate using conventional methods, i.e. PROT, FAT, and CHOAVLDF (total carbohydrate by difference $<$ CHODF $>$ minus dietary fiber) is not always $100 \%$. DGs for protein and fat are determined by nutritional epidemiology studies, and in most of these studies percent energy from protein and fat are estimated using conventional methods [3]. As mentioned, percent energy from protein and fat using PROCTAA and FATLEA are usually less than the percent energy from protein and fat using PROT and FAT, respectively. Therefore, it is important to compare the calculated percent energy from protein and fat using PROCTAA and FATLEA to DGs for protein and fat. Further studies on the utilization of SFTCJ and Dietary Reference Intakes for Japanese are needed.

\section{Conclusion}

Conclusion should reflect and elucidate how the results correspond to the study presented and provide a concise explanation of the allegation of the findings.

\section{Acknowledgements}

We would like to thank Editage (www.editage.jp) for English language editing.

\section{Conflict of Interest}

No conflicts of interest to be declared.

\section{Bibliography}

1. The United Nations Food and Agriculture Organization. Food energy-methods of analysis and conversion factors. Report of a technical workshop Rome. FAO Food and Nutrition (2002): 77.

2. The Council for Science and Technology. Ministry of Education, Culture, Sports, Science, and Technology. Standard Tables of Food Composition in Japan -2020. Report of the Subdivision on Resources (2020).

3. Ito S and Sasaki S. "Dietary Reference Intakes for Japanese 2020". Daiichi-shuppan, Tokyo (2020): 106-170.

4. Rand WM., et al. "Meta-analysis of nitrogen balance studies for estimating protein requirements in healthy adults". American Journal of Clinical Nutrition 77.1 (2003): 109-127.

\section{Assets from publication with us}

- Prompt Acknowledgement after receiving the article

- Thorough Double blinded peer review

- Rapid Publication

- Issue of Publication Certificate

- High visibility of your Published work

Website: www.actascientific.com/

Submit Article: www.actascientific.com/submission.php Email us: editor@actascientific.com

Contact us: +919182824667 